\title{
Assessment of Corrosion Rate of Reinforcing Steel in Concrete Using Galvanostatic Pulse Transient Technique
}

\author{
Hyoung-Seok So ${ }^{1) *}$ and Stephen Geoffrey Millard ${ }^{2)}$
}

(Received April 24, 2007, Accepted December 18, 2007)

\begin{abstract}
This paper discusses a method of measuring transient potential response of a corrosion interface to a small galvanostatic pulse perturbation for a rapid assessment of the corrosion rate of reinforcing steel in concrete structures. Measurements were taken on $100 \mathrm{~mm}$ sections of steel bars which were subjected to a wide range of corrosion conditions, from passive steel to actively corroding steel. The duration of the applied galvanostatic pulse was varied between $5 \mathrm{~s}$ and $180 \mathrm{~s}$, and the lateral distance of the point of measurement on the steel bar varied from zero to $400 \mathrm{~mm}$. The result of the electrochemical transient response was investigated using a typical sampling rate of $1 \mathrm{kHz}$. Analysis of the transient potential response to the applied galvanostatic pulse has enabled the separation of equivalent electronic components so that the components of a series of capacitances and resistances, whose values are dependent on the corrosion condition of the reinforcing steel, could be isolated. The corrosion rate was calculated from a summation of the separate resistive components, which were associated with the corrosion interface, and was compared with the corrosion rate obtained from linear polarization resistance (LPR) method. The results show that the galvanostatic pulse transient technique enables the components of the polarization resistance to be evaluated separately so as to give more reliable corrosion rate values than those obtained from the LPR method. Additionally, this paper shows how the galvanostatic pulse transient response technique can be implemented. An appropriate measurement time for passive and actively corroding reinforcing steel is suggested for the galvanostatic pulse transient response measurements in the field site.
\end{abstract}

Keywords: corrosion rates, concrete, transient pulse, potential, assessment

\section{Introduction}

Corrosion of reinforcing steel in concrete structures is internationally recognized as a primary factor for its effective service lifetime. Considerable effort has been extended over the past two decades in research and development of assessing the corrosion of steel bars in reinforced concrete. However, an effective means of quantifying corrosion rates of reinforced concrete structures in the field site is not yet available.

A number of electrochemical techniques have been developed to assess the corrosion equilibrium and the corrosion rate of reinforcing steel so as to enable the estimation of the remaining service life of a reinforced concrete structure. The most established technique among these is half-cell potential mapping, ${ }^{1}$ but this method gives an evaluation of where the corrosion activity is likely only and no quantitative assessment of the rate of corrosion. Thus an area identified as a high risk will corrode quickly and develop into an immediate problem, requiring an urgent attention, or it may be corroding very slowly and does not require a remedial/preventative action.

${ }^{1)} \mathrm{KCI}$ Member, Dept. of Architectureal Engineering, Seonam University, Namwon 590-711, Korea. Email: sohs01@paran.com

${ }^{2}$ Dept. of Engineering, University of Liverpool, Liverpool L69 3GQ, UK.

Copyright (C) 2007, Korea Concrete Institute. All rights reserved, including the making of copies without the written permission of the copyright proprietors.
Linear polarization resistance (LPR) method $^{2}$ has been developed to provide a direct measurement of the corrosion rate of reinforcing steel in concrete. It has grown in its popularity during recent years for the evaluation of reinforced concrete structures subjected to the risk of corrosion attack. A stepped DC perturbation is applied to the steel reinforcement in corrosion equilibrium from the surface of concrete. After a pre-determined delay time, during which a new equilibrium is re-established, the steady-state response to the perturbation is measured. For the example of a galvanostatic LPR, a small current perturbation $I_{\text {app }}$ is applied, and the resulting change in electrochemical potential $\mathrm{V}_{\max }$ is measured. The polarisation resistance $\mathrm{R}_{\mathrm{p}}$ can be computed from $I_{\text {app }}$ and $V_{\text {max }}$. In many cases, it has been found that as long as the maximum deviation, $\mathrm{V}_{\max }$, from the equilibrium potential is less than $30 \mathrm{mV}$, the rate of corrosion is inversely proportional to $R_{p}$. An alternative way of taking LPR measurements with similar results is the potentiostatic LPR. A small potential perturbation $(\Delta \mathrm{E})$ is applied, and the resulting current response $(\Delta \mathrm{I})$ is measured.

Although the LPR method has significant advantages over potential mapping and offers a means of direct evaluation of ongoing rate of corrosion, there are some drawbacks and errors inherent with this approach. First, the polarization resistance is measured not from the surface of the steel reinforcement but from the surface of the concrete, and thus it incorporates a resistance component attributable to the concrete cover zone. The concrete resistance must be independently measured and 
subtracted from the overall the polarisation resistance measured from surface of the concrete. Another problem is the choice of a suitable equilibration time when the current response to the applied potential shift is to be measured. The selection of an inappropriate measurement time, where the new equilibrium has not been fully established, can cause significant errors. Even when the effect of the concrete resistance is compensated for, the measured $R_{p}$ may contain other resistance components not directly related to the corrosion activity on the surface of the steel such as slow diffusion effects within the concrete and fast surface skin effects, but these cannot be separated from the $R_{p}$. Thus, in order to calculate the corrosion rate accurately, it is necessary to select a suitable measurement time required to evaluate processes directly associated with corrosion but to exclude processes associated with the surface concrete zone.

In this study, a relatively new technique, which is the galvanostatic pulse transient response technique ${ }^{3-5}$ has been investigated in an attempt to overcome some of the aforementioned difficulties. Using this approach, an incremental galvanostatic pulse perturbation was applied to the steel reinforcement from the surface of the concrete in the same manner for galvanostatic LPR measurement. Instead of waiting for a new electrochemical potential equilibrium to be established after applying the current perturbation and before measuring the potential change, the transient response itself was measured. Analysis of this transient response allows a resistor/ capacitance model of the system to be established, enabling more accurate evaluation of corrosion rate than the evaluation by LPR method.

\section{Experimental procedure}

The transient galvanostatic pulse and linear polarization resistance (LPR) measurements were conducted on short lengths of mild steel bars embedded in a $400 \times 600 \times 100 \mathrm{~mm}$ concrete slab with a compressive strength of $40 \mathrm{~N} / \mathrm{mm}^{2}$ and water-to-cement ratio of $60 \%$ as shown in Fig. 1. The monitoring bars measured $10 \mathrm{~mm}$ in diameter and $100 \mathrm{~mm}$ in length with a cover thickness of $40 \mathrm{~mm}$, and they were electrically isolated from other steel bars so that any corrosion measurement taken upon the surface area of the steel bar would be precisely known. The surface area of all monitoring bars was measured at $31.42 \mathrm{~cm},{ }^{2}$ and they are labelled $\mathrm{N} 1, \mathrm{~N} 2, \mathrm{C} 1$ and $\mathrm{C} 2$. The $\mathrm{C} 1$ and $\mathrm{C} 2$ monitoring bars were embedded in chloride contaminated $(5 \% \mathrm{NaCl})$ concrete to promote corrosion. The concrete test slab was placed outdoors in a coastal marine environment of a UK city (Liverpool) for approximately seven years, and it was exposed to natural ambient temperature fluctuations and rainfall.

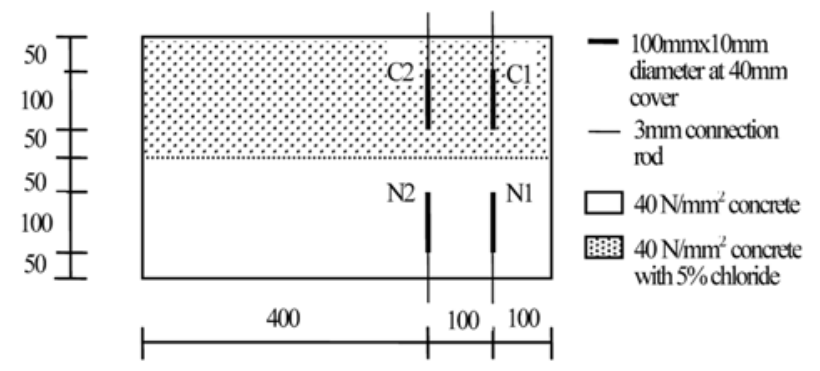

Fig. 1 Specification details of the test slab.

\subsection{Galvanostatic pulse transient measurement}

A three-electrode measurement system as shown in Fig. 2 was employed. Current was applied to the reinforcing steel bar from the brass auxiliary electrode $(150 \times 100 \mathrm{~mm})$ connected to the surface of the concrete using a damp sponge, and the transient potential of the steel bar was measured against the central reference electrode (silver/silver chloride). A battery-powered constant current source was built for this experiment to apply the current perturbation. The current source allowed the selection of a stable supply of $1,0.1$ and $0.01 \mathrm{~mA}$ current to be applied. The resultant transient voltage response was monitored using a 16-bit data acquisition facility. The measurement time was selected from the range of $5 \mathrm{~s}$ to $180 \mathrm{~s}$, and a typical sampling rate of $1 \mathrm{kHz}$ was used to collect the dynamic response data. A current perturbation provided an initial potential shift between 20 $30 \mathrm{mV}$, which is within the linear region as recommended by Stern-Geary. ${ }^{6}$ Thus, initial tests were always conducted using the smallest possible pulse. If this did not perturb the system sufficiently, the steel bar was allowed to re-equilibrate, and the current was increased to achieve the desired potential shift. In this study, all results of the tests undertaken on actively corroding steel samples fell within this linear region. However, most of the results of the tests conducted on passive steel bars manifested a potential shift larger than that of the linear region, even when the smallest possible pulse of $0.01 \mathrm{~mA}$ was used. This may result in some inaccuracies in the resolution of the components of the transient. However, the corrosion rate of the passive steel bars is so small that errors in measurement due to the perturbed potential falling outside the linear region were deemed to be insignificant.

The collected data for transient potential response were analysed to obtain an equivalent electronic circuit ${ }^{7}$ as shown in Fig. 3. In many cases, a simple Randles circuit can be used to model the concrete cover zone and the reinforcing steel corrosion interface. At time t, the transient electrochemical potential response $\mathrm{V}_{\mathrm{t}}$ to a current perturbation $\mathrm{I}_{\text {app }}$ (Fig. 4) is given by

$$
V_{t}=I_{a p p} R_{\Omega}+I_{a p p} R_{c t}\left[1-\exp \left(\frac{-t}{R_{c c} C_{d l}}\right)\right]
$$

In this circuit, $R_{\Omega}$ represents the ohmic resistance of the concrete cover zone between the surface electrode and the steel bar. $\mathrm{C}_{\mathrm{dl}}$ represents a double layer capacitance at the surface of the steel bar, and $\mathrm{R}_{\mathrm{ct}}$ represents the corrosion charge transfer resistance at

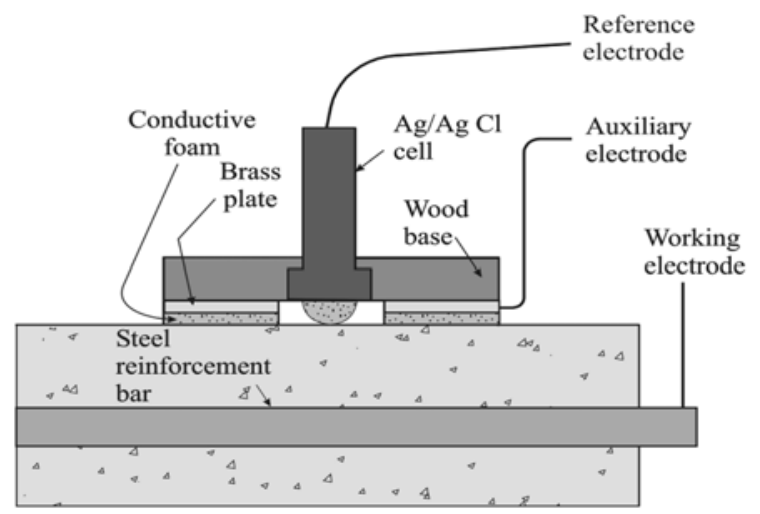

Fig. 2 Three-electrode measurement for the reinforcing steel in concrete. 


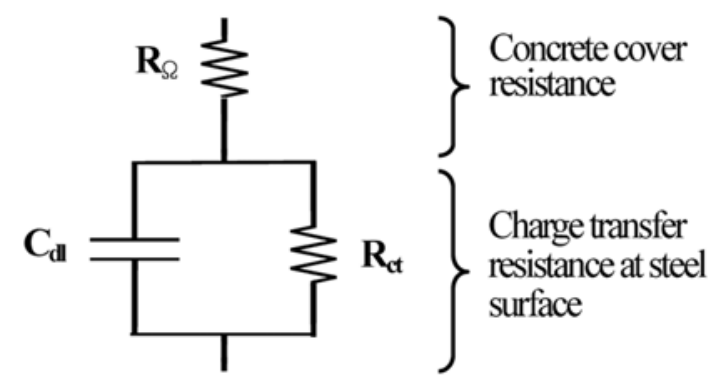

Fig. 3 Simple Randles circuit. $^{7}$

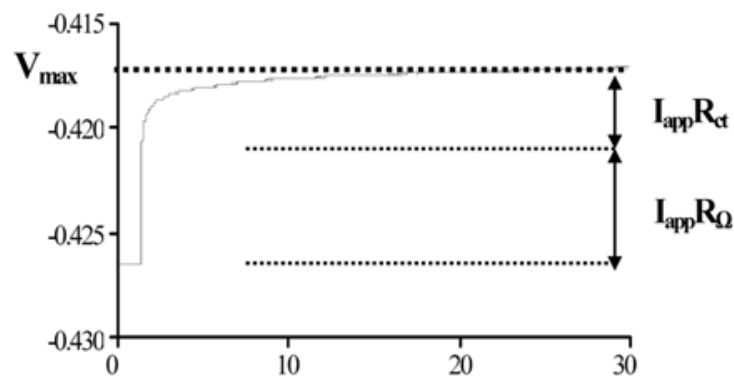

Fig. 4 Transient potential response for $\mathrm{C} 1$.

the surface of the steel bar. After a suitable equilibration time, the transient response reaches a steady-state potential $\left(\mathrm{V}_{\text {max }}\right)$, expressed in the following equation.

$$
V_{\text {max }}-V_{t}=I_{a p p} R_{c t} \exp \left(\frac{-t}{R_{c c} C_{d l}}\right)
$$

Equation (2) can be expressed as in Eq. (3) by logarithmic transformation.

$$
\log _{e}\left(V_{\max }-V_{t}\right)=\ln \left(I_{a p p} R_{c t}\right) \frac{-t}{R_{c t} C_{d l}}
$$

A plot of $\log _{\mathrm{e}}\left(\mathrm{V}_{\max }-\mathrm{V}_{\mathrm{t}}\right)$ against time $\mathrm{t}$ gives a linear graph with a slope of $1 / \mathrm{R}_{\mathrm{ct}} \mathrm{C}_{\mathrm{dl}}$ and an intercept on the vertical axis of $\ln$ $\left(\mathrm{I}_{\text {app }} \mathrm{R}_{\mathrm{ct}}\right)$, as shown in Figs. 4 and 5. Hence, $\mathrm{R}_{\mathrm{ct}}$ and $\mathrm{C}_{\mathrm{dl}}$ can be obtained for the evaluation.

However, the reinforcing steel corrosion interface of the concrete is more complicated than a simple Randles model of a resistor in parallel with a single capacitor, and experimental results from the corroding system may be better modelled as a series of resistorcapacitor parallel components. The linear section of the plot of $\log _{\mathrm{e}}\left(\mathrm{V}_{\max }-\mathrm{V}_{\mathrm{t}}\right)$ against $\mathrm{t}$ may be used successively over different time periods to extract corresponding values of resistance and capacitance (Fig. 5). Hence, the separated components can be analyzed by extracting each successive section, and the resistance and capacitance can be determined for each component. Knowing the values of the resistance and capacitance enables the time constant for these components to be calculated as the product of $\mathrm{R}_{\mathrm{ct}}$ and $\mathrm{C}_{\mathrm{dl}}$. Each component of the system may be associated with a different process occurring within the system. Some of these components may be associated with the corrosion process, while others may be associated with other phenomena such as ionic diffusion effect of the bulk concrete or the dielectric properties of the environment. The values of capacitance and the time constant may be used to decide which one of the associated resistances

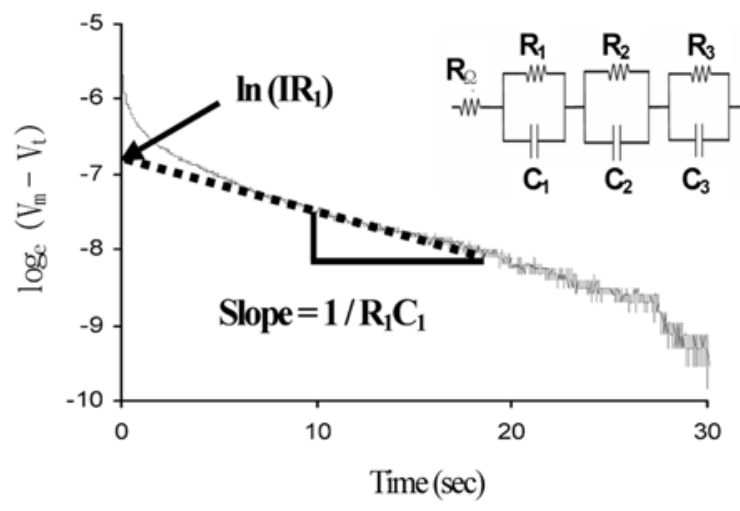

Fig. 5 Plot of $\log _{e}\left(V_{\max }-V_{t}\right)$ against time for $C 1$.

can be attributed to the interfacial corrosion process. The ohmic component of the resistance due to the concrete cover zone may be evaluated from the initial potential shift at time zero, i.e. instantaneously as the current is switched on.

Thus, the corrosion current $\left(\mathrm{I}_{\text {corr }}\right)$ can be calculated using the Eq. (4) from the polarization resistance $\left(\mathrm{R}_{\mathrm{ct}}\right)$ that sums up each of the individual resistance associated with the corrosion process but leaves out other resistances from the overall resistance.

$$
I_{\text {corr }}=\frac{B}{R_{c t}}
$$

where B is the Stern-Geary constant, which is normally assumed to be $25 \mathrm{mV}$ for active corrosion ${ }^{8}$ and $50 \mathrm{mV}$ for passivity. ${ }^{9}$

\subsection{Linear polarization resistance measurement}

Linear polarization resistance (LPR) measurements were conducted on the same bars using a three-electrode system equipment, using the galvanostatic pulse transient method (Fig. 1). When taking potentiostatic LPR measurements, the reinforcing steel was polarized instantaneously to $10 \mathrm{mV}(\Delta \mathrm{E})$ in a positive direction from the rest potential, and the current was allowed to equilibrate for a selected period of time, i.e. 90s. At the end of this equilibrium period, the polarization resistance $\left(R_{p}\right)$ was calculated using the following equation:

$$
R_{p}=\frac{\Delta E}{\Delta I}
$$

However, it is necessary to compensate $R_{p}$ for the solution resistance $R_{\Omega}$ (i.e. the resistance of the concrete cover zone) due to its incorporation into the measurement. $\mathrm{R}_{\Omega}$ was determined by taking a $300 \mathrm{~Hz}$ AC resistance measurement prior to the LPR measurement. The charge transfer resistance $R_{c t}$ controls the rate of corrosion current $\mathrm{I}_{\text {corr }}$, which may be calculated as

$$
I_{\text {corr }}=\frac{B}{R_{p}-R_{\Omega}}=\frac{B}{R_{c t}}
$$

Additionally,

$$
I_{\text {corr }}=\frac{I_{\text {corr }}}{A}
$$

where $\mathrm{B}$ is the Stern-Geary constant, $\mathrm{i}_{\text {corr }}$ is the corrosion current density, $\mathrm{A}$ is the surface area of the steel bar being polarized.

A small current perturbation $\mathrm{I}_{\text {app }}(\Delta \mathrm{I})$ was applied in order to take galvanostatic LPR measurements, and the resulting change 
in electrochemical potential $\mathrm{V}_{\max }(\Delta \mathrm{E})$ was then measured after a new equilibrium was established (i.e. 90s). The charge transfer resistance $\left(\mathrm{R}_{\mathrm{ct}}\right)$ and corrosion rate $\left(\mathrm{i}_{\text {corr }}\right)$ were calculated in the same way using Eqs. (5)-(7).

Typical polarization resistances and corrosion rates $\left(\mathrm{i}_{\text {corr }}\right)$ for the steel bar in concrete structures are shown in Table $1 .^{10}$

\section{Results and discussion}

A typical electrochemical potential transient response to the applied current is depicted in Fig. 4. The initial instantaneous rise is due to the ohmic solution resistance $\mathrm{R}$, i.e. the resistance of the concrete cover zone. $\mathrm{R}$ is first calculated and subtracted from the transient data. The remaining potential transient response data were analyzed to determine a number of separate resistive components with different time constants. It can be seen from Eq. (3) that a plot of $\log _{e}\left(V_{\max }-V_{t}\right)$ against $t$ (time) will give a linear graph with a slope of $1 / \mathrm{R}_{\mathrm{ct}} \mathrm{C}_{\mathrm{dl}}$ and an intercept on the vertical axis of $\ln$ $\left(I_{a p p} R_{c t}\right)$ as illustrated in Fig. 5. The analysis of the potential transients in this study enabled between two and four separate resistive and capacitive components to be determined for each of the systems measured. The galvanostatic pulse transient results are presented in Tables $2 \sim 5$, and the LPR results are provided in Table 6. A comparison of corrosion rates evaluated from the galvanostatic pulse transient and LPR measurements is summarized in Table 7. From the magnitude of corrosion rate $i_{\text {corr }}$ shown in

Table 1 Typical corrosion rates for steel bars in a concrete structure. $^{10}$

\begin{tabular}{c|c|c}
\hline Rate of corrosion & $R_{\mathrm{ct}}\left(\mathrm{k} \Omega \mathrm{cm}^{2}\right)$ & $i_{\text {corr }}\left(\mathrm{A} / \mathrm{cm}^{2}\right)$ \\
\hline \hline Very high & 0.25 to 2.5 & 10 to 100 \\
\hline High & 2.5 to 25 & 1 to 10 \\
\hline Low/moderate & 25 to 250 & 0.1 to 1 \\
\hline Passive & $<250$ & $<0.1$ \\
\hline
\end{tabular}

Table 2 Results for an actively corroding steel bar C1 at different lateral distances (90s pulse and $0.01 \mathrm{~mA}$ ).

\begin{tabular}{l|c|c|c|c|c}
\hline \multirow{2}{*}{ Resistance $\left(\mathrm{k} \Omega \mathrm{cm}^{2}\right)$} & \multicolumn{5}{|c}{ Lateral Distances $(\mathrm{mm})$} \\
\cline { 2 - 6 } & 0 & 100 & 200 & 300 & 400 \\
\hline \hline $\mathrm{R}_{\Omega}$ & 18 & 31 & 43 & 56 & 75 \\
\hline $\mathrm{R}_{1}\left(\mathrm{C}_{1}>1,000 \mu \mathrm{F} / \mathrm{cm}^{2}\right)$ & 7.5 & 7.8 & 10.0 & 11.4 & 13.0 \\
\hline $\mathrm{R}_{2}\left(100<\mathrm{C}_{2}>1,000 \mu \mathrm{F} / \mathrm{cm}^{2}\right)$ & 5.3 & 5.6 & 4.7 & 5.5 & 5.7 \\
\hline $\mathrm{R}_{3}\left(10<\mathrm{C}_{3}>100 \mu \mathrm{F} / \mathrm{cm}^{2}\right)$ & 3.7 & 4.0 & 3.4 & 3.5 & 4.2 \\
\hline $\mathrm{R}_{4}\left(1<\mathrm{C}_{4}>10 \mu \mathrm{F} / \mathrm{cm}^{2}\right)$ & 4.0 & 4.0 & 2.7 & 4.7 & 4.3 \\
\hline
\end{tabular}

Table 3 Results for a passive steel bar N1 at different lateral distances (90s pulse and $0.01 \mathrm{~mA}$ )

\begin{tabular}{l|c|c|c|c|c}
\hline \multirow{2}{*}{ Resistance $\left(\mathrm{k} \Omega \mathrm{cm}^{2}\right)$} & \multicolumn{5}{|c}{ Lateral distances $(\mathrm{mm})$} \\
\cline { 2 - 6 } & 0 & 100 & 200 & 300 & 400 \\
\hline \hline $\mathrm{R}_{\Omega}$ & 28 & 34 & 38 & 44 & 54 \\
\hline $\mathrm{R}_{1}\left(50<\mathrm{C}_{1}>100 \mu \mathrm{F} / \mathrm{cm}^{2}\right)$ & 928 & 1041 & 992 & 862 & 913 \\
\hline $\mathrm{R}_{2}\left(30<\mathrm{C}_{2}>50 \mu \mathrm{F} / \mathrm{cm}^{2}\right)$ & 65 & 87 & 60 & 51 & 52 \\
\hline $\mathrm{R}_{3}\left(10<\mathrm{C}_{3}>30 \mu \mathrm{F} / \mathrm{cm}^{2}\right)$ & 36 & 40 & 24 & 30 & 20 \\
\hline $\mathrm{R}_{4}\left(1<\mathrm{C}_{4}>10 \mu \mathrm{F} / \mathrm{cm}^{2}\right)$ & - & - & 11 & 9.6 & 8.0 \\
\hline
\end{tabular}

Table 1, Bars $\mathrm{C} 1$ and $\mathrm{C} 2$, which were embedded in chloride contaminated concrete, can be classified as actively corroding steel with a high corrosion rate, but bars $\mathrm{N} 1$ and $\mathrm{N} 2$ can be categorized as passive steel based on the galvanostatic pulse transient and LPR results.

\subsection{Determination of time constants by the corrosion processes}

Analysis of the potential transients enabled a number of separate components with different time constants to be identified. Examining the separate components, the values of capacitance so evaluated may be used to decide which one of the associated

Table 4 Results for an actively corroding steel bar $\mathbf{C} 1$ at different measurement time $(0.01 \mathrm{~mA}$ pulse).

\begin{tabular}{c|c|c|c|c|c|c|c|c|c|c|c}
\hline $\mathrm{t}(\mathrm{s})$ & $\mathrm{R}_{\Omega}\left(\mathrm{k} \Omega \mathrm{cm}^{2}\right)$ & $\mathrm{R}_{1}\left(\mathrm{k} \Omega \mathrm{cm}^{2}\right)$ & $\mathrm{C}_{1}\left(\mu \mathrm{F} / \mathrm{cm}^{2}\right)$ & $\mathrm{R}_{2}\left(\mathrm{k} \Omega \mathrm{cm}^{2}\right)$ & $\mathrm{C}_{2}\left(\mu \mathrm{F} / \mathrm{cm}^{2}\right)$ & $\mathrm{R}_{3}\left(\mathrm{k} \Omega \mathrm{cm}^{2}\right)$ & $\mathrm{C}_{3}\left(\mu \mathrm{F} / \mathrm{cm}^{2}\right)$ & $\mathrm{R}_{4}\left(\mathrm{k} \Omega \mathrm{cm}^{2}\right)$ & $\mathrm{C}_{4}\left(\mu \mathrm{F} / \mathrm{cm}^{2}\right)$ & $\Sigma \mathrm{R}_{\mathrm{ct}}\left(\mathrm{k} \Omega \mathrm{cm}^{2}\right)$ & $\mathrm{i}_{\mathrm{cor}}\left(\mu \mathrm{A} / \mathrm{cm}^{2}\right)$ \\
\hline \hline 5 & 12.5 & $\mathbf{4 . 6}$ & 439 & $\mathbf{4 . 2}$ & 59 & $\mathbf{2 . 4}$ & 12 & - & - & 11.2 & 2.23 \\
\hline 10 & 12.5 & $\mathbf{5 . 3}$ & 543 & $\mathbf{4 . 1}$ & 55 & $\mathbf{2 . 8}$ & 8.0 & - & - & 12.2 & 2.05 \\
\hline 30 & 12.5 & 5.3 & 2,724 & $\mathbf{3 . 7}$ & 466 & $\mathbf{4 . 2}$ & 40 & $\mathbf{2 . 3}$ & 7.6 & 10.2 & 2.45 \\
\hline 60 & 12.5 & 7.1 & 3,751 & $\mathbf{3 . 6}$ & 679 & $\mathbf{4 . 2}$ & 53 & $\mathbf{2 . 8}$ & 7.8 & 10.6 & 2.35 \\
\hline 90 & 12.5 & 7.9 & 5,110 & $\mathbf{3 . 9}$ & 899 & $\mathbf{4 . 7}$ & 52 & $\mathbf{2 . 8}$ & 7.6 & 11.4 & 2.19 \\
\hline 180 & 12.5 & 15.3 & 5,963 & $\mathbf{3 . 8}$ & 696 & $\mathbf{4 . 5}$ & 50 & $\mathbf{2 . 7}$ & 7.7 & 11.0 & 2.27 \\
\hline
\end{tabular}

*Resistances in bold are deemed to be directly associated with corrosion process.

Table 5 Results for a passive steel bar $\mathbf{N} 1$ at different measurement time $(0.01 \mathrm{~mA}$ pulse).

\begin{tabular}{|c|c|c|c|c|c|c|c|c|c|c|c|}
\hline $\mathrm{t}(\mathrm{s})$ & $\mathrm{R}_{\Omega}\left(\mathrm{k} \Omega \mathrm{cm}^{2}\right)$ & $\mathrm{R}_{1}\left(\mathrm{k} \Omega \mathrm{cm}^{2}\right)$ & $\mathrm{C}_{1}\left(\mu \mathrm{F} / \mathrm{cm}^{2}\right)$ & $\mathrm{R}_{2}\left(\mathrm{k} \Omega \mathrm{cm}^{2}\right)$ & $\mathrm{C}_{2}\left(\mu \mathrm{F} / \mathrm{cm}^{2}\right)$ & $\mathrm{R}_{3}\left(\mathrm{k} \Omega \mathrm{cm}^{2}\right)$ & $\mathrm{C}_{3}\left(\mu \mathrm{F} / \mathrm{cm}^{2}\right)$ & $\mathrm{R}_{4}\left(\mathrm{k} \Omega \mathrm{cm}^{2}\right)$ & $\mathrm{C}_{4}\left(\mu \mathrm{F} / \mathrm{cm}^{2}\right)$ & $\sum \mathrm{R}_{\mathrm{ct}}\left(\mathrm{k} \Omega \mathrm{cm}^{2}\right)$ & $\mathrm{i}_{\text {corr }}\left(\mu \mathrm{A} / \mathrm{cm}^{2}\right)$ \\
\hline 5 & 29.9 & 235 & 12 & 57 & 13 & - & - & - & - & 292 & 0.086 \\
\hline 10 & 29.9 & 374 & 15 & 86 & 18 & - & - & - & - & 460 & 0.054 \\
\hline 30 & 29.9 & 752 & 21 & 149 & 38 & - & - & - & - & 901 & 0.028 \\
\hline 60 & 29.9 & 1,066 & 26 & 165 & 56 & - & - & - & - & 1,231 & 0.020 \\
\hline 90 & 29.9 & 1,214 & 28 & 141 & 70 & - & - & - & - & 1,355 & 0.018 \\
\hline 180 & 29.9 & 1,392 & 33 & 80 & 163 & 69 & 25 & 24 & 7.1 & 1,565 & 0.016 \\
\hline
\end{tabular}

*Resistances in bold are deemed to be directly associated with corrosion process. 
resistances can be attributed to the interfacial corrosion process in a manner similar to that used for AC impedance. ${ }^{11,13}$ However, it is difficult to select confidently which resistive (to the corrosion processes) components should be included in the evaluation of the polarization resistance $\mathrm{R}_{\mathrm{c}}$, because the values of capacitance can be changed by several factors such as measurement time, etc.

In a series of experiments to investigate this issue further, a galvanostatic pulse transient measurement was carried out on the monitoring bars, $\mathrm{C} 1$ (actively corroding steel with a high corrosion rate) and N1 (passive steel) with the auxiliary/reference electrode assembly positioned at different lateral distances away from the bar along the surface of the slab. The reasoning behind this was that the part of the response due to the steel and concrete corrosion interface component should remain constant, whereas the part of the response due to the concrete should change, while the auxiliary/reference electrode assembly was moved away from the bar. Thus, it should be feasible to identify which components of the equivalent electronic circuit are associated with corrosion process. The results are summarized in Tables 2 and 3.

The results for an actively corroding steel bar (C1), as shown in Table 2, can serve as a good guide to which resistances obtained from the galvanostatic pulse transient technique may be linked to a corrosion process. The resistance of the concrete cover zone $\mathrm{R}_{\Omega}$ increases as the lateral distance from the bar is increased as expected, because there is more concrete between the bar and the reference electrode. It can be also seen that the resistance $R_{1}$ increases as the lateral distance to the bar is increased, and these are all associated with larger capacitances (greater than $1,000 \mu \mathrm{F} /$ $\mathrm{cm}^{2}$ ). However the resistances $R_{2}, R_{3}$ and $R_{4}$ remain relatively constant as the lateral distance from the bar is increased. Therefore the resistance $\mathrm{R}_{1}$ is deemed not to be associated with corrosion in the steel/concrete interface, and it is more likely to be due to the diffusion effects in the concrete.

Table 3 indicates different results for a passive steel bar (N1). The resistance of the concrete cover zone $\mathrm{R}$ increases as the lateral distance from the bar is increased, also, but all resistances $\left(R_{1} \sim R_{4}\right)$ stay constant with the lateral distance of the measurement away from the bar, indicating that it may be related to the corrosion process.

Table 4 shows the variation of the resistances and capacitances

Table 6 Results of LPR measurements (90s pulse).

\begin{tabular}{c|c|c|c|c}
\hline \multirow{2}{*}{ Bar } & \multicolumn{2}{|c|}{ Galvanostatic LPR } & \multicolumn{2}{c}{ Potentiostatic LPR } \\
\cline { 2 - 5 } & $\mathrm{R}_{\Omega}\left(\mathrm{k} \Omega \mathrm{cm}^{2}\right)$ & $\mathrm{R}_{\mathrm{ct}}\left(\mathrm{k} \Omega \mathrm{cm}^{2}\right)$ & $\mathrm{R}_{\Omega}\left(\mathrm{k} \Omega \mathrm{cm}^{2}\right)$ & $\mathrm{R}_{\mathrm{ct}}\left(\mathrm{k} \Omega \mathrm{cm}^{2}\right)$ \\
\hline \hline $\mathrm{C} 1$ & 15.7 & 32.9 & 17.2 & 35.2 \\
\hline $\mathrm{C} 2$ & 16.1 & 25.2 & 18.5 & 51.0 \\
\hline $\mathrm{N} 1$ & 21.6 & 2,500 & 20.8 & 3,125 \\
\hline $\mathrm{N} 2$ & 22.2 & 1,136 & 22.0 & 1,136 \\
\hline
\end{tabular}

with different time constants in the separated components for the actively steel bar $\mathrm{C} 1$, when different measurement times were selected. It shows that the resistance $R_{1}$ increases with increased measurement time, but the resistances $R_{2}, R_{3}$ and $R_{4}$ are not significantly changed. In addition, the value of capacitance associated with this resistance $\left(\mathrm{R}_{1}\right)$ also increases significantly with an increase in the measurement time, particularly after 30s. However the capacitances measured from passive steel were not sensitive to the selection of measurement time, as shown in Table 5. Newton et al. ${ }^{12}$ reported that the impedance of actively corroding steel in concrete included a component from the ionic diffusion resistance due to the bulk concrete.

As shown in the above results, it follows that the resistance of components associated with very high capacitances greater than $1000 \mu \mathrm{F} / \mathrm{cm}^{2}$ could be attributable to the ionic diffusion resistance within the bulk concrete and should be disregarded in the evaluation of the polarization resistance $\mathrm{R}_{\mathrm{ct}}$.

Table 4 also shows that an increase in the selected measurement time did not have a significant influence on the resistance components. It indicates that a measurement time of only $5 \mathrm{~s}$ would be sufficient for complete stabilization of the response. This is due to the corrosion process for steel bars with a high corrosion rate being controlled by components with relatively fast time constants. However, Table 5 shows a different situation for the passive steel, and it indicates also that the corrosion process of passive steel is controlled by components associated with much longer time constants (i.e. the time taken for an equilibrium to be reached is much longer). This shows also that the measurement time of $90 \mathrm{~s}$ is needed to measure accurately the slowest time constant associated with the corrosion processes for passive steel in concrete. For practical purposes, a measurement time of $30 \mathrm{~s}$ seems to give the closest general approximation for both actively corroding steel and passive steel. However, it is also deemed significant that those components with capacitances greater than $1,000 \mu \mathrm{F} / \mathrm{cm}^{2}$ had time constants in the range 30 s or less for an actively corroding steel bars. Hence, these components might be inadvertently be included in the evaluation of corrosion rates extracted from LPR corrosion measurements, which often uses an equilibration period of 30 seconds.

\subsection{Comparison of corrosion rates determined by galvanostatic pulse transient and LPR technique}

LPR measurements were conducted on the same bars using both the potentiostatic and galvanostatic LPR method, and the results are summarized in Table 6 . It can be seen that the corrosion rates determined from galvanostatic LPR method were higher than those evaluated from potentiostatic LPR.

Table 7 shows ongoing corrosion rates calculated from LPR measurements and galvanostatic pulse transient experiments. For a direct comparison between two techniques, the corrosion rates

Table 7 Corrosion rates evaluated using galvanostatic pulse transient and LPR method (90s pulse).

\begin{tabular}{c|c|c|c|c|c|c|c|c}
\hline Bar & \multicolumn{3}{|c|}{ Galvanostatic pulse transient method } & \multicolumn{2}{c|}{ Galvanostatie LPR } & \multicolumn{2}{c}{ Potentiostatic LPR } \\
\hline \hline $\mathrm{C} 1$ & 19.3 & 1.3 & 11.4 & 2.19 & 32.9 & 0.76 & 35.2 & 0.71 \\
\hline $\mathrm{C} 2$ & 32.1 & 0.78 & 16.7 & 1.5 & 25.2 & 0.99 & 51.0 & 0.49 \\
\hline $\mathrm{N} 1$ & 13.55 & 0.018 & 13.55 & 0.018 & 25.00 & 0.01 & 31.25 & 0.008 \\
\hline $\mathrm{N} 2$ & 781 & 0.032 & 781 & 0.032 & 11.36 & 0.022 & 11.36 & 0.022 \\
\hline
\end{tabular}


from galvanostatic pulse transient measurements were calculated by summing all of the separated resistance components or by subtracting those resistances associated with very high capacitances greater than $1,000 \mu \mathrm{F} / \mathrm{cm}^{2}$ from the overall sum.

Corrosion rates calculated from using LPR technique generally were lower than those calculated using galvanostatic pulse transient response technique. The differences in the corrosion rates fell within a factor of 3 for all steel bars, and were more evident at higher corrosion rates.

It was not expected the corrosion rates would fluctuate significantly in one-day time interval between the collection of the LPR data and the galvanostatic pulse transient data.

Table 7 also shows that the corrosion rates calculated from the galvanostatic pulse transient data are significantly greater due to the subtraction of those resistive components with associated capacitances greater than $1,000 \mu \mathrm{F} / \mathrm{cm}^{2}$.

Therefore the results show that the galvanostatic pulse transient method has the advantage of making the separation of resistance components possible, and it enables those resistances not associated with corrosion to be discounted. This indicates that the galvanostatic pulse transient technique is able to give more reliable corrosion rates of steel bars in concrete than those achievable through LPR method.

\section{Conclusions}

1) The galvanostatic pulse transient response technique in this study enabled between two and four pairs of resistive and capacitive components of reinforcing steel bars in concrete to be identified.

2) The galvanostatic pulse transient results at a specific measurement time for actively corroding steel show that the resistance of components associated with high capacitance greater than $1,000 \mu \mathrm{F} / \mathrm{cm}^{2}$ are more likely to be related to the diffusion effect of the bulk concrete and unrelated directly to the corrosion activity.

3) In addition, those components with very high capacitances had time constants in the range 30 s or less for an actively corroding steel bar. Hence, these components might be inadvertently be included in the evaluation of corrosion rates, extracted from LPR corrosion measurements, which often used an equilibration period of 30 seconds.

4) The exclusion of resistive components based on high capacitance increased the corrosion rate evaluated by a factor of up to 2.0.

5) For passive steel, the influence of measurement time on the evaluation of rate of corrosion is significant due to the resistances associated with longer time constant related to the corrosion process. However, for all practical purposes, a measurement time of $30 \mathrm{~s}$ seems to yield the result of the closest general approximation for both the active steel and the passive steel.

6) The corrosion rates calculated from the galvanostatic pulse transient data are generally higher than those evaluated by LPR technique. These differences fell within a factor of 3.0.

7) Overall, the results obtained show that the galvanostatic pulse transient technique is able to provide more reliable corrosion rates of steel bars in concrete than those achievable through LPR technique.

\section{Acknowledgements}

The authors would like to thank the Korea Research Foundation for founding this work (grant reference KRF-2005-000-10067).

\section{References}

1. American Society for Testing and Materials, Standard Test Method for Half-Cell Potentials of Uncoated Reinforcing Steel in Concrete, C876-91, ASTM, Philadelphia, PA, 1991.

2. Millard, S. G, Gowers, K. R., and Gill, R. P., "Practical Field Measurement of Reinforcement Corrosion in Concrete Using Linear Polarization Methods," British Journal of NonDestructive Testing, Vol.34, No.9, 1992, pp.444 452.

3. Law, D. W., Millard, S. G, and Bungey, J. H., "Use of Galvanostatic Pulse Measurements on Active Reinforcing Steel in Concrete to Assess Corrosion Rates," British Corrosion Journal, Vol.36, No.1, 2001, pp.75 80.

4. Gonzalez, J. A., Miranda, J. M., and Feliu S., "Considerations on Reproducibility of Potential and Corrosion Rate Measurements in Reinforced Concrete," Corrosion Science, Vol.46, 2004, pp.2467 2485.

5. Sathiyanarayanan, S., Natarajan, P., Saravanan, K., Srinivasan, S., and Venkatachari, G., "Corrosion Monitoring of Steel in Concrete by Galvanostatic Pulse Technique," Cement and Concrete Composites, Vol.28, 2006, pp.630 637.

6. Stern, M. and Geary, A. L., "Electrochemical Polarisation: I. Theoretical Analysis of the Shape of Polarization Curves," Journal of the Electrochemical Society, Vol.104, No.1, 1957, pp.56 63.

7. Randles, J. E. B., "Kinetics of Rapid Electrode Reactions," Discussion of the Faraday Society, Vol.1, No.1, 1947, pp.11 19.

8. Broomfield J. P., "Corrosion of Steel in Concrete Understanding”, Investigation and repair, E\&FN Spon, 1997, 201pp.

9. Andrade, C. and Alonso, C., "Corrosion Rate Monitoring in the Laboratory and On-Site," Construction and Building Materials, Vol.10, No.5, 1996, pp.315 322.

10. Broomfield, J. P., "Techniques to Assess the Corrosion Activity of Steel-reinforced Concrete Structures", ASTM STP 1276, eds. N. S. Berke, E. Escalante, C. K. Nmai, D. Whiting, West Conshohocken, PA: ASTM, 1996, pp.91 106.

11. Gower, K. R. and Millard, S. G., "Electrochemical Techniques for Corrosion Assessment of Reinforced Concrete Structures," Proceeding of Institute Civil Engineering, Structures and Bridges, Vol.134, May 1999, pp.129 137.

12. Newton, C. J. and Sykes, J. M., "A Galvanostatic Pulse Technique for Investigation of Steel Corrosion in Concrete," Corrosion Science, Vol.28, No.11, 1988, pp.1051 1073.

13. Schiegg, Y., Online-monitoring to Detect Corrosion of Rebars in Reinforced Concrete, PhD Thesis, No.14583, ETH Zurich, 2002. 